\title{
Differential Expressed Genes and Pathways Associated with Disease Severity In Siblings with Cystic Fibrosis
}

\author{
İlksen Ekinci ${ }^{1}$, Mina Hızal ${ }^{1}$, Nagehan Emiralioğlu ${ }^{1}$, ugur ozcelik ${ }^{1}$, Ebru Yalcin ${ }^{1}$, Deniz \\ Dogru $^{1}$, Nural Kiper ${ }^{1}$, and Didem Dayangaç-Erden ${ }^{1}$ \\ ${ }^{1}$ Hacettepe University Faculty of Medicine
}

July 13, 2020

\begin{abstract}
Cystic fibrosis is an autosomal recessive disease caused by CFTR gene mutations. Despite having the same mutation, CF patients may demonstrate clinical variability in severity and prognosis of the disease. In this study, we aimed to determine differentially expressed genes and associated molecular pathways between mild and severe siblings with same genotype. We performed targeted real-time PCR based transcriptomic analysis of nasal epithelial cells obtained from two families with two siblings with Class II mutations (F508del/F508del) and (F508del/G85E), one family with three siblings with Class IV mutation (I1234V/I1234V). In severe siblings with Class II mutations, TNFRSF11A, KCNE1, STX1A, SLC9A3R2 were found to be up regulated. CXCL1, CFTR, CXCL2 were found to be down regulated. Inflammation-immune response related signaling pathways such as IL-17, NF-kappa B, TNF, NOD-like receptor signaling were identified. In the severe sibling with Class IV mutation; inflammation and immune response-related pathways were discovered. Also, AGE-RAGE and TLR signaling were found to be specific to Class IV group. Comparison of CF patients to non-CF control; showed that ICAM1 was up regulated whereas EZR, TNFRSF1A, HSPA1A were down regulated in patients. In addition, a significant positive correlation was determined between differentially expressed genes in AGE-RAGE, cytokine-cytokine receptor interaction, insulin resistance and hepatic involvement in $\mathrm{CF}$ patients. As a result of this study, differentially expressed genes and associated pathways responsible for clinical severity among affected siblings carrying the same mutation were identified. The results will provide an opportunity for the development of novel target molecules for treatment of disease.
\end{abstract}

\section{Introduction}

Cystic fibrosis $(\mathrm{CF})$, which is one of the most common autosomal recessive diseases in Caucasian populations caused by mutations in the Cystic Fibrosis Transmembrane Conductance Regulator (CFTR) gene. The gene encodes for an ion channel located in the apical membrane of epithelial cells which transports chloride ions and bicarbonate. ${ }^{1}$ To date, over 2000 mutations have been reported in the CFTR gene. Mutations have been classified into seven groups that affect the production of CFTR protein (Class IA and IB), its trafficking (Class II), its conductance (Class III and Class IV), its function (Class V) and its stability (Class VI) ${ }^{2}$. Although CF is characterized by chronic progressive lung disease it also affects sweat glands, liver, pancreas, upper airway, intestine and reproductive systems. ${ }^{3}$

Especially Pseudomonas aeruginosa and Staphlyococcus aureus cause chronic lung infection in patients and lung disease is the primary reason for mortality and morbidity in $\mathrm{CF}^{4,5}$. As a result of defective CFTR protein in the pancreas approximately $60-80 \%$ of patients have exocrine pancreatic insufficiency ${ }^{6,7}$. Additionally, dysfunction in the pancreas causes CF-related diabetes (CFRD) ${ }^{8}$. On the other hand, CFTR protein is necessary for the stability of mucus acidity and hydration in the intestine and regulation of bile secretion in the liver. ${ }^{9}$ Meconium ileus occurs in approximately 5-20\%, CF liver disease (CFLD) occurs in 5\%-10\% 
of patients. ${ }^{9,10}$ Another affected system in CF is the reproductive system. CF patients with mild CFTR mutations have been shown to be associated with congenital bilateral absence of vas deferens (CBAVD). ${ }^{11,12}$

Since CF is described as a multisystem disorder it is difficult to establish genotype-phenotype correlation. Interestingly, some studies have found that patients with the same genotype demonstrated variable disease severity. ${ }^{13,14,15}$ Especially studies conducted on twins and siblings with the same CFTR mutation but different clinical symptoms, suggested that CF-related genes and genes that interact with CFTR protein may play a role in clinical heterogeneity. ${ }^{16,17}$ In recent years, there have been transcriptomic approaches in order to characterize phenotypic variability comparing $\mathrm{CF}$ patients to healthy controls or mild to severe CF patients with the same CFTR mutation. ${ }^{18,19}$ However, there is no transcriptomic study that includes mild and severe siblings from families where families share the same genetic origin. In the present study, we performed targeted transcriptomic analysis to identify differentially expressed genes and associated molecular pathways between mild and severe siblings.

\section{Materials and Methods}

Patients

A total of seven CF patients which belong to three families (Family 1: F1- P1, F1-P2, Family 2: F2-P1, F2-P2, Family 3: F3-P1, F3-P2, F3-P3) and three non-CF control subjects (C1, C2, C3) were diagnosed at Hacettepe University Faculty of Medicine Department of Pediatric Pulmonology. Ethical approval was obtained from Hacettepe University Non-Interventional Clinical Research Ethics Board (Project No: TYL-2019-17977). Informed written consent was obtained from the parents of all patients and non-CF control subjects. Clinical severity of siblings were determined according to recurrent lung infection, hepatic involvement, FEV1\% (predicted) and CFRD parameters. Consanguinity was detected in two families (F2 and F3). The detailed clinical parameters of siblings were described in Table 1 . The study also included three age matched non-CF control subjects who have no chronic disease history and no respiratory symptoms. They also have normal physical examination and do not take medications.

TABLE 1 Clinical and genetic parameters of siblings in three CF families.

\begin{tabular}{|c|c|c|c|c|c|c|c|}
\hline & Family 1 & Family 1 & Family 2 & Family 2 & Family 3 & Family 3 & Family 3 \\
\hline \multirow{3}{*}{ Genotype } & Patient 1 & Patient 2 & Patient 1 & Patient 2 & Patient 1 & Patient 2 & Patient 3 \\
\hline & F508del/ & F508del/ & F508del/ & F508del/ & $\mathrm{I} 1234 \mathrm{~V} /$ & $\mathrm{I} 1234 \mathrm{~V} /$ & $\mathrm{I} 1234 \mathrm{~V} /$ \\
\hline & G85E & G85E & F508del & F508del & $\mathrm{I} 1234 \mathrm{~V}$ & I1234V & I1234V \\
\hline \multicolumn{2}{|c|}{ ConsanguinityNo } & No & Yes & Yes & Yes & Yes & Yes \\
\hline Gender & Male & Female & Male & Female & Male & Male & Female \\
\hline $\begin{array}{l}\text { Age at } \\
\text { sample } \\
\text { collection } \\
\text { (years) }\end{array}$ & 12 & 16 & 6 & 3 & 7 & 19 & 9 \\
\hline $\begin{array}{l}\text { Age at } \\
\text { diagnosis }\end{array}$ & 3 months & 4 months & 5 months & 1 week & 5,5 years & 16 years & 6 years \\
\hline $\begin{array}{l}\text { Sweat } \\
\text { chloride } \\
\text { concen- } \\
\text { tration } \\
(\text { mmol } / \mathrm{L})\end{array}$ & 96 & 110 & 101 & 96 & 88 & 80 & 150 \\
\hline $\begin{array}{l}\text { FEV1 (\% } \\
\text { pre- } \\
\text { dicted) }\end{array}$ & 88 & 105 & NA & NA & 99 & 89 & 53 \\
\hline
\end{tabular}




\begin{tabular}{|c|c|c|c|c|c|c|c|}
\hline & Family 1 & Family 1 & Family 2 & Family 2 & Family 3 & Family 3 & Family 3 \\
\hline $\begin{array}{l}\text { History } \\
\text { of } \\
\text { pseudo- } \\
\text { bartter } \\
\text { syn- } \\
\text { drome }\end{array}$ & Yes & No & Yes & Yes & No & No & Yes \\
\hline $\begin{array}{l}\text { Meconium } \\
\text { ileus }\end{array}$ & No & No & No & No & No & No & No \\
\hline Malabsorpsio & Wes & Yes & Yes & Yes & Yes & Yes & Yes \\
\hline $\begin{array}{l}\text { Recurrent } \\
\text { lung } \\
\text { infection }\end{array}$ & No & No & Yes & $\begin{array}{l}\text { Yes, } \\
\text { Progressive }\end{array}$ & No & Yes & $\begin{array}{l}\text { Yes, } \\
\text { Progressive }\end{array}$ \\
\hline Comorbidity & $\begin{array}{l}\text { Mild hepatic } \\
\text { involvement }\end{array}$ & $\begin{array}{l}\text { Severe } \\
\text { hepatic } \\
\text { involvement } \\
\text { with } \\
\text { cirrhosis, } \\
\text { CFRD }^{1}\end{array}$ & $\begin{array}{l}\text { Mild hepatic } \\
\text { involvement }\end{array}$ & $\begin{array}{l}\text { Severe } \\
\text { hepatic } \\
\text { involvement }\end{array}$ & No & No & No \\
\hline Pancreatitis & No & No & No & No & No & Yes & No \\
\hline $\begin{array}{l}\text { Disease } \\
\text { severity }\end{array}$ & Mild & Severe & Mild & Severe & Mild & Intermediate & Severe \\
\hline Treatment & $\begin{array}{l}\text { Multivitamin } \\
\text { supple- } \\
\text { mentation, } \\
\text { Salt re- } \\
\text { placement } \\
\text { therapy, } \\
\text { Mucolytic } \\
\text { therapy, } \\
\text { PERT }^{2} \text {, } \\
\text { Antibiotics }\end{array}$ & $\begin{array}{l}\text { Multivitamin } \\
\text { supple- } \\
\text { mentation, } \\
\text { Salt re- } \\
\text { placement } \\
\text { therapy, } \\
\text { Mucolytic } \\
\text { therapy, } \\
\text { PERT }^{2} \text {, } \\
\text { Antibiotics }\end{array}$ & $\begin{array}{l}\text { Multivitamin } \\
\text { supple- } \\
\text { mentation, } \\
\text { Salt re- } \\
\text { placement } \\
\text { therapy, } \\
\text { Mucolytic } \\
\text { therapy, } \\
\text { PERT }^{2} \text {, } \\
\text { Antibiotics }\end{array}$ & $\begin{array}{l}\text { Multivitamin } \\
\text { supple- } \\
\text { mentation, } \\
\text { Salt re- } \\
\text { placement } \\
\text { therapy, } \\
\text { Mucolytic } \\
\text { therapy, } \\
\text { PERT }^{2} \text {, } \\
\text { Antibiotics }\end{array}$ & $\begin{array}{l}\text { Multivitamin } \\
\text { supple- } \\
\text { mentation, } \\
\text { Salt re- } \\
\text { placement } \\
\text { therapy, } \\
\text { Mucolytic } \\
\text { therapy, } \\
\text { PERT }^{2} \text {, } \\
\text { Antibiotics }\end{array}$ & $\begin{array}{l}\text { Multivitamin } \\
\text { supple- } \\
\text { mentation, } \\
\text { Salt re- } \\
\text { placement } \\
\text { therapy, } \\
\text { Mucolytic } \\
\text { therapy, } \\
\text { PERT }^{2} \text {, } \\
\text { Antibiotics }\end{array}$ & $\begin{array}{l}\text { Multivitamin } \\
\text { supple- } \\
\text { mentation, } \\
\text { Salt re- } \\
\text { placement } \\
\text { therapy, } \\
\text { Mucolytic } \\
\text { therapy, } \\
\text { PERT }^{2} \text {, } \\
\text { Antibiotics }\end{array}$ \\
\hline
\end{tabular}

${ }^{1}$ CF-related diabetes. ${ }^{2}$ Pancreatic enzyme replacement therapy. NA: Not applicable; The pulmonary function test is applied only to patients 6 years old and above.

DNA Sequence Analysis

Peripheral blood samples were collected for DNA sequencing to determine CFTR mutations in siblings. Genomic DNA was isolated by the salting-out method. CFTR coding regions, exon-intron boundaries, promoter and 3'UTR were amplified in Gene Amplification PCR System 9700 (Applied Biosystem, USA). Standard $\mathrm{PCR}$ reaction was performed using the with $5 \mathrm{U} / \mu \mathrm{L}$ Taq DNA polymerase (Ampliqon, Denmark), 12,5 mM each dNTPs (Fermantas, USA), $100 \mathrm{nM}$ forward and reverse primer, 10X ammonium buffer (Ampliqon, Denmark) and $100 \mathrm{ng} / \mu \mathrm{l}$ input genomic DNA per reaction. PCR conditions were, 35 cycle: $94^{\circ} \mathrm{C} / 30$ seconds; denaturation, $57^{\circ} \mathrm{C} / 45$ seconds; annealing, $72^{\circ} \mathrm{C} / 30$ seconds; extension. The PCR products were checked in 3\% agarose gel electrophoresis containing ethidium bromide (Sigma-Aldrich, USA). After genomic DNA amplification, Sanger DNA sequencing was carried out in ABI 3030 (Thermo-Fisher Scientific, USA).

Nasal Respiratory Epithelial Cell Collection and RNA Isolation

Nasal brushings were obtained from the mucosal surface using a $0.8 \mathrm{~mm}$ interdental brush (TePe, Ireland). The nasal brush was then transferred immediately to $600 \mu$ lysis buffer (Exiqon, Germany) containing $6 \mu l$ 
$\beta$-mercaptoethanol (Sigma-Aldrich, USA) and gently pushed through a sterile pipette tip to release the lysate into the lysis buffer. Brushings from two nostrils were pooled. Total RNA was isolated usingmiRCURYTM RNA Isolation Kit (Exiqon, Germany). Lysate transferred to the lysis buffer was homogenized and after Proteinase K (Thermo Fisher Scientific, USA) treatment, it was transferred to mini spin column (Exiqon, Germany). After DNase I treatment (Bio-Rad), total RNA was eluted in RNase free $\mathrm{H}_{2} \mathrm{O}$. Total RNA was stored at $-80{ }^{\circ} \mathrm{C}$. RNA quality and quantity was determined using NanoDrop ND-1000 (Thermo Fisher Scientific, USA).

cDNA Synthesis and Human Cystic Fibrosis RT ${ }^{2}$ Profiler PCR Array

For cDNA synthesis, $1000 \mathrm{ng} / \mu$ total RNA was carried out using $\mathrm{RT}^{2}$ First Strand Kit (Qiagen, Germany). cDNA was then added to the RT ${ }^{2}$ SYBR Green qPCR Master Mix (Qiagen). $25 \mu$ of each sample was aliquotted on 96-well format $\mathrm{RT}^{2}$ Profiler PCR Arrays (Qiagen). The Human Cystic Fibrosis RT ${ }^{2}$ Profiler PCR Array which uses qRT-PCR based technique consists of 84 genes involved in CF and CFTRrelated genes and pathways (Neutrophil chemotaxis; CCL2, CXCR2, EDN1, IL1B, EDNRA, CXCL8 and ITGB2. Immune and inflammatory response; CXCL1/2/8, TNFRSF1A/11A, ACE, IL1B, IL6/10, TGFB1, TLR2/4/5, DEFB1, NFKBIA, NFKB1, ICAM1. Protein folding; HSP90AA1, HSPA1A, HSPA4/8, HSPH1. Ion transport; SCNN1B/G, KCNE1, SLC9A3R1, ADK, NR4A2. Oxidative stress; MBL2, NOS3, CLU, DUSP1, GCLC, LCN2, MSRA, PTGS2, SFTPB), five housekeeping genes (ACTB, B2M, GAPDH, HPRT1 and RPLP0), one genomic DNA control, three reverse-transcription controls and three positive PCR controls. All steps were done according to the manufacturer's protocol for the Bio-Rad Iq-5 real-time PCR system.

Statistical Analysis

For data analysis, a MS-Excel sheet was downloaded from the manufacturer's website (https://www.qiagen.com) NormFinder (https://moma.dk/normfinder-software) was used to select the best housekeeping genes for normalization. ACTB and HPRT1 were found as the most stable combination of housekeeping genes in the patients and non-CF control subjects. Gene expression results were calculated using the $2^{-\Delta \Delta^{\prime} \mathrm{T}}$ method. Unpaired student t-test was performed to compare differentially expressed genes between mild/severe siblings and patients/healthy controls (p[?]0.05, 2-fold change (FC)). The pathway enrichment analysis was performed using WebGestalt tool. (http://www.webgestalt.org/).

\section{Results}

Detection of CFTR Genotype and Evaluation of Clinical Parameters in Siblings

As a result of DNA sequencing, the CFTR genotype of siblings were identified as follows: Family 1, F1-P1, F1-P2, F508del/G85E (Class II); Family 2, F2-P1, F2-P2, F508del/F508del (Class II); Family 3, F3-P1, F3P2, F3-P3, I1234V/I1234V (Class IV). Siblings in family 1 were evaluated for pulmonary findings, hepatic involvement and other comorbid conditions. 16-year-old F1-P2 had CFRD and severe hepatic involvement with cirrhosis and waiting for liver transplantation but 12-year-old F1-P1 had mild hepatic involvement and was not diagnosed with CFRD during his follow-up. For this reason, F1-P2 was found to have severe phenotype and F1-P1 to have mild phenotype. In family 2, siblings were evaluated for pulmonary findings and hepatic involvement. Younger sibling F2-P2 had severe hepatic involvement with chronic liver disease, recurrent lung infections and severe pulmonary disease compared with F2-P1. Therefore, F2-P2 was evaluated as severe and F2-P1 as mild phenotype. Siblings in family 3 were evaluated for recurrent lung infections, pulmonary function tests and severity of pulmonary disease. According to pulmonary findings F3-P1 was evaluated to be mild, F3-P2 intermediate and F3-P3 who died due to respiratory insufficiency had severe phenotype.

Differentially Expressed Genes Between Mild and Severe Patients with Class II Mutation

DAmong 29 differentially expressed genes (Table S1), Tumor Necrosis Factor Receptor Superfamily, Member $11 \mathrm{~A}$ (TNFRSF11A; RANK, p=0.01), Potassium Voltage-Gated Channel (KCNE1, p=0.02), Syntaxin 1A (STX1A, p=0.008) and Solute Carrier Family 9 Member 3 Regulator 2 (SLC9A3R2; NHERF-2, p=0.03) 
demonstrated significant upregulation in severe (F1-P2 and F2-P2) compared to mild (F1-P1 and F2-P1) patients. On the other hand, Chemokine (CXC motif) Ligand 1 (CXCL1, $\mathrm{p}=0.02)$, CFTR ( $\mathrm{p}=0.04)$ and Chemokine (CXC motif) Ligand 2 (CXCL2, $\mathrm{p}=0.03$ ) demonstrated significant decreased expression in severe patients (Figure 1).

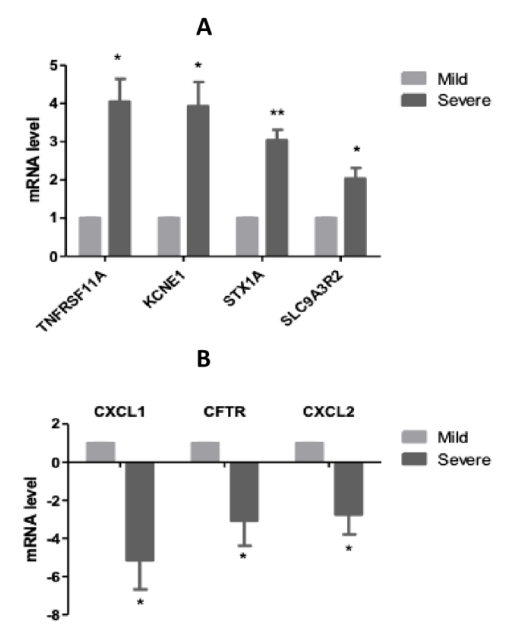

FIGURE 1 Differentially expressed genes in severe patients with Class II mutation. Significance was analyzed with unpaired Student t-test. **: p[?]0.01; *: p[?]0.05. (A) Up regulated genes (TNFRSF11A; 4,03 FC, KCNE1; 3,90 FC, STX1A; 3,03 FC and SLC9A3R2; 2,02 FC). (B) Down regulated genes (CXCL1; -5,03 FC, CFTR; -2,92 FC and CXCL2; -2,65 FC).

Among the KEGG pathways that were enriched in WebGestalt analysis, IL-17 signaling pathway, NF-kappa B signaling pathway, cytokine-cytokine receptor interaction, TNF signaling pathway, NOD-like receptor signaling pathway, chemokine signaling pathway, SNARE interactions in vesicular transport and aldosterone regulated sodium reabsorption were the most prominent ones which could be important in CF severity due to their roles in inflammation. Pathways and associated genes were summarized in Table 2. Possible mechanism of inflammation related pathways in severe patients with Class II mutation was illustrated in Figure 2.

TABLE 2 The list of pathways and differentially expressed genes in severe patients with Class II mutation (Significantly expressed genes are shown in bold).

\begin{tabular}{|c|c|}
\hline Name of the pathway & Associated genes \\
\hline IL-17 signaling pathway & $\boldsymbol{C X} \boldsymbol{C L} 1, \mathrm{LCN} 2, \boldsymbol{C} \boldsymbol{X} \boldsymbol{C L} 2$, IL1B, CXCL8, HSP90AA1, PTGS2, S100A8 \\
\hline NF-kappa B signaling pathway & CXCL2, CXCL8, IL1B, PTGS2, TNFRSF11A, TNFRSF1A \\
\hline Cytokine-cytokine receptor interaction & CXCL1, $\boldsymbol{C X C L} 2$, CXCL8, IL1B, TNFSF10, CXCR2, TNFRSF11A, TNF \\
\hline TNF signaling pathway & $C X \boldsymbol{C L} 1, \boldsymbol{C X} \boldsymbol{C L} 2, \mathrm{IL} 1 \mathrm{~B}, \mathrm{PTGS2}$, TNFRSF1A \\
\hline NOD-like receptor signaling pathway & 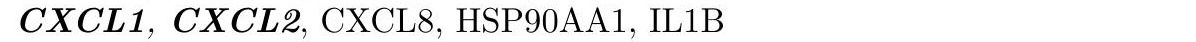 \\
\hline Chemokine signaling pathway & CXCL1, CXCL2, CXCL8 \\
\hline SNARE interaction in vesicular transport & SNAP23, STX1A \\
\hline Aldosterone regulated sodium reabsorption & SCNN1G, SLC9A3R2 \\
\hline
\end{tabular}




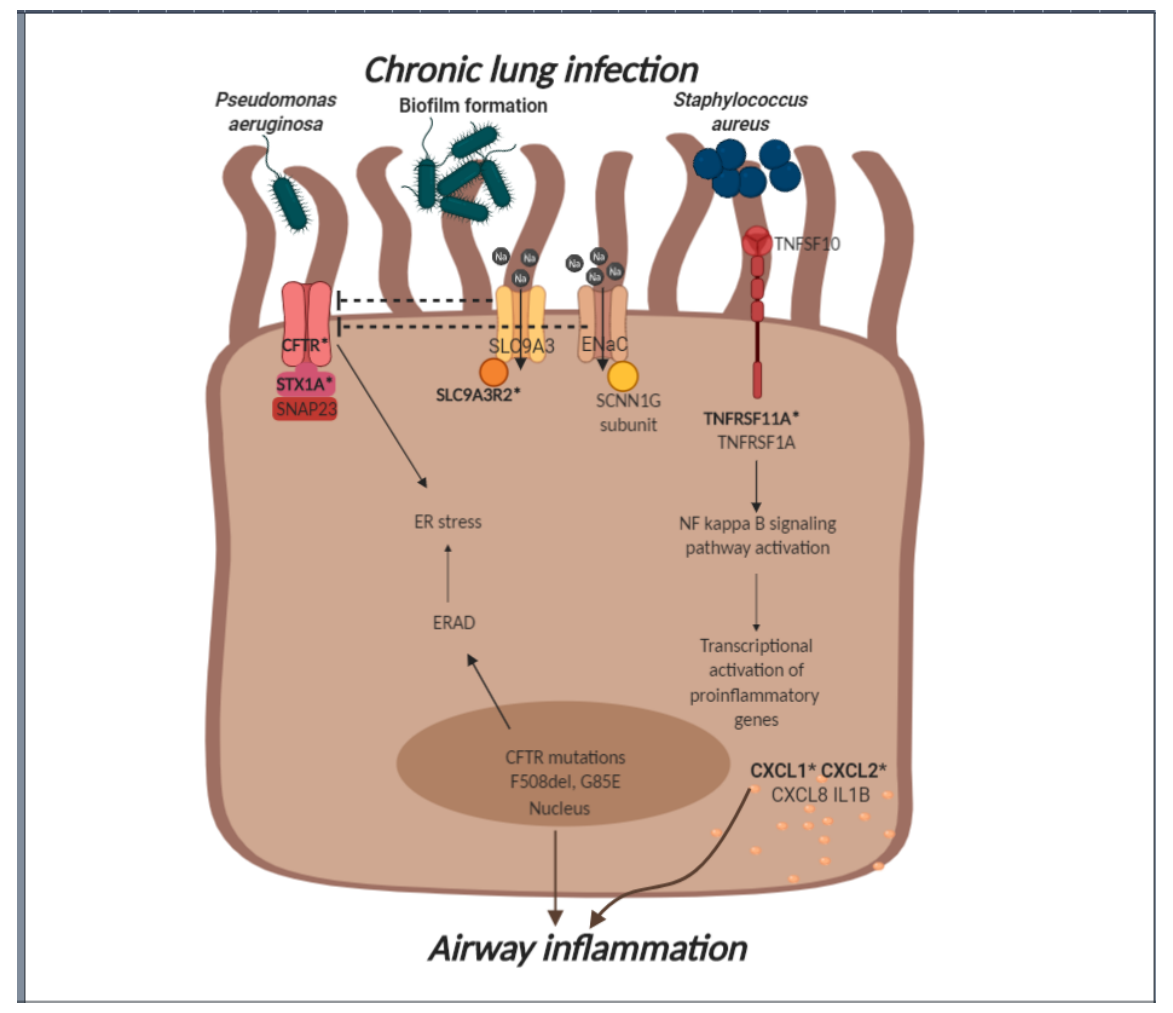

FIGURE 2 Illustration of inflammation-related mechanisms in severe patients with Class II mutation. TNFSF10-TNFRSF11A/1A cytokine-cytokine receptor interaction causes activation of NF kappa B signaling pathways and release of proinflammatory genes such as CXCL1/2/8 and IL1B. On the other hand, G85E and F508del-CFTR undergo endoplasmic reticulum-associated degradation (ERAD) which is a protein quality control system. The accumulation of misfolded proteins in the ER, causes ER stress. Downregulation of CFTR activates CFTR interaction protein STX1A and STX1A binding partner SNAP23. Also, CFTR negative regulator subunits SLC9A3R2 and SCNN1G are upregulated. All the mentioned pathways above causes airway inflammation in Class II group severe patients (Significant differentially expressed genes are shown in bold and asterisk).

Differentially Expressed Genes Between Mild and Severe Patients with Class IV Mutation

A total of 24 genes were demonstrated to be differentially expressed (Table 3). Three of them were up regulated while 21 genes were down regulated in severe sibling (F3-P3) compared to mild siblings (F3-P1 and F3-P2). Although the statistical significance of differentially expressed genes could not be evaluated, pathways were interpreted in terms of biological significance. Among the KEGG pathways that were enriched in WebGestalt analysis, the IL-17 signaling pathway $(\mathrm{p}=4.48 \mathrm{E}-09)$, NOD-like receptor signaling pathway $(\mathrm{p}=2.75 \mathrm{E}-07)$, AGE-RAGE signaling pathway in diabetic complications $(\mathrm{p}=7.24 \mathrm{E}-06)$, cytokine-cytokine receptor interaction $(\mathrm{p}=1.17 \mathrm{E}-05)$, NF-kappa $\mathrm{B}$ signaling pathway $(\mathrm{p}=5.91 \mathrm{E}-06)$, TNF signaling pathway $(\mathrm{p}=1.21 \mathrm{E}-05)$, and TLR signaling pathway $(\mathrm{p}=0.0001)$ were found to be associated with severity in Class IV.

TABLE 3 The differentially expressed genes in severe patient with Class IV mutation.

\begin{tabular}{llc}
\hline Up regulated genes & Description & FC \\
\hline DEFB1 & Defensin beta 1 & 2,33 \\
CCL2 & C-C motif chemokine ligand 2 & 2,29
\end{tabular}




\begin{tabular}{lll}
\hline Up regulated genes & Description & FC \\
\hline CLU & Clusterin & 2,11 \\
Down regulated genes & Description & FC \\
IL7R & Interleukin 7 receptor & $-9,43$ \\
IGFBP5 & Insulin-like growth factor binding protein 5 & $-7,27$ \\
KCNE1 & Potassium voltage-gated channel, member 1 & $-5,44$ \\
NOS3 & Nitric oxide synthase 3 & $-5,09$ \\
MBL2 & Mannose-binding lectin 2 & $-4,88$ \\
SERPINA1 & Serpin peptidase inhibitor, clade A, member 1 & $-4,63$ \\
PLA2G5 & Phospholipase A2, group 5 & $-4,42$ \\
CXCR & C-X-C motif chemokine receptor 2 & $-4,38$ \\
SFTPB & Surfactant protein B & $-4,18$ \\
ACE & Angiotensin I converting enzyme 1 & $-3,80$ \\
HSPH1 & Heat shock 105kDa/110kDa & $-3,75$ \\
ITGB2 & Integrin, beta 2 & $-3,55$ \\
CFTR & Cystic fibrosis transmembrane conductance regulator & $-3,29$ \\
DUSP1 & Dual specificity phosphatase 1 & $-3,20$ \\
TLR4 & Toll-like receptor 4 & $-3,18$ \\
IL1B & Interleukin 1, beta & $-2,91$ \\
CXCL8 & C-X-C motif chemokine ligand 8 & $-2,30$ \\
PTGS2 & Prostaglandin-endoperoxide synthase 2 & $-2,22$ \\
CXCL1 & C-X-C motif chemokine ligand 1 & $-2,13$ \\
HSP90AA1 & Heat shock protein 90 alpha family class A member 1 & $-2,10$ \\
TNF & Tumor necrosis factor & $-2,07$ \\
\hline
\end{tabular}

Similar to severe patient with Class II mutation, pathways involved in inflammation and immune response were also defined in severe patient with Class IV mutation. But advanced glycation end products and receptor of advanced glycation end products (AGE-RAGE) signaling pathway in diabetic complications ( $\mathrm{p}=7.24 \mathrm{E}-$ 06) and TLR signaling pathway $(\mathrm{p}=0.0001)$ were found to be specific to Class IV group. Possible molecular mechanism was summarized in Figure 3.

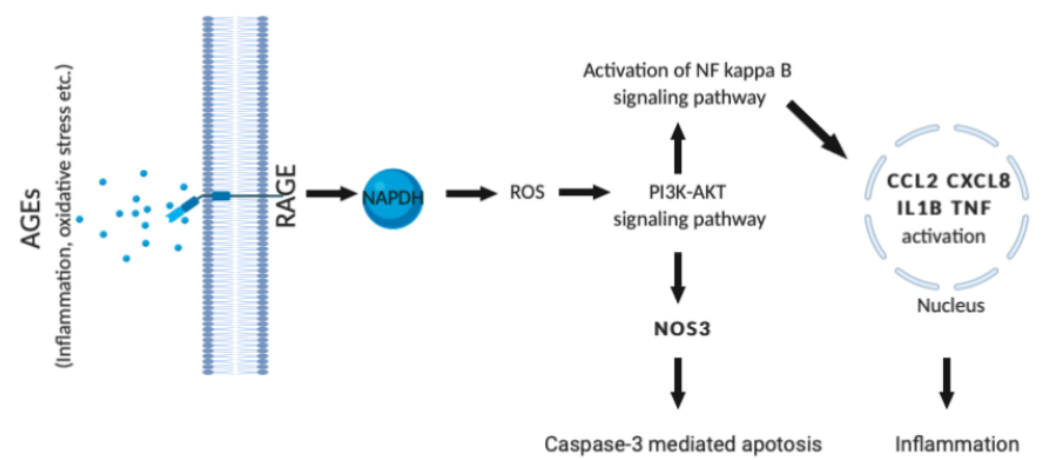

FIGURE 3 Mechanism of AGE-RAGE pathway and associated genes in severe patient with Class IV mutation. AGE ligands bind to its receptors called RAGE. RAGE induced NAPDH production triggers ROS reactive oxygen species (ROS) that is resulted in PI3K-AKT signaling pathway activation and NOS3 
mediated apoptosis. Also, PI3K-AKT signaling pathway trigger NF-kappa B signaling pathway and induce inflammation mechanism in the severe sibling (Genes associated with AGE-RAGE signaling pathway in diabetic complications are shown in bold.).

Differentially Expressed Genes Between CF Patients and non-CF Control Subjects

Among 39 differentially expressed genes (Table S2), Intercellular Adhesion Molecule 1 (ICAM1; 4,29 FC, $\mathrm{p}=0.03$ ) was significantly upregulated whereas Ezrin (EZR; -7,27 FC, p=0.02), Tumor Necrosis Factor Receptor Superfamily, Member $1 \mathrm{~A}$ (TNFRSF1A; -2,43 FC, p=0.01) and Heat Shock 70kDa Protein $1 \mathrm{~A}$ (HSPA1A; -2,39 FC, $\mathrm{p}=0.006$ ) were significantly down regulated in $\mathrm{CF}$ patients compared to non-CF control subjects (Figure 4).

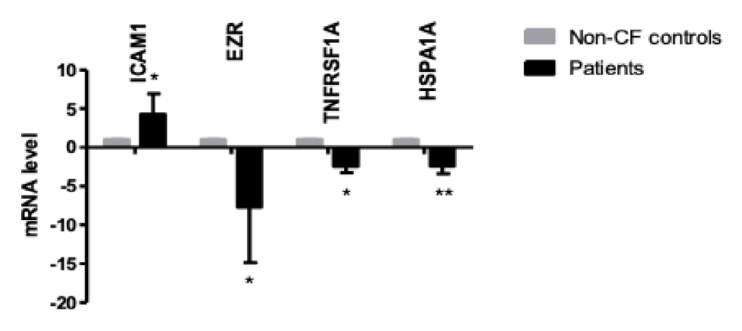

FIGURE 4 Differentially expressed genes in CF patients (Family 1, 2 and 3). Significance was analyzed with unpaired student t-test. **: p[?]0.01; *: p[?]0.05. Up regulated gene (ICAM1; 4,29 FC). Down regulated genes (HSPA1A; -2,39 FC, TNFRSF1A; -2,43 FC and EZR; -7,27 FC).

Among the KEGG pathways that were enriched in WebGestalt analysis pathways involved in inflammation and immune response such as TNF signaling ( $\mathrm{p}=8.38 \mathrm{E}-13)$, NF-kappa B signaling $(\mathrm{p}=6.69 \mathrm{E}-09)$, insulin resistance $(7.08 \mathrm{E}-06)$ and cytokine-cytokine receptor interaction $(\mathrm{p}=4.19 \mathrm{E}-06)$ were detected as the most significant ones (Table 4).

TABLE 4 The list of pathways and differentially expressed genes in CF patients (Significantly expressed genes are shown in bold).

\begin{tabular}{ll}
\hline Name of the pathway & Associated genes \\
\hline TNF signaling pathway & CCL2, CXCL1, CXCL2, EDN1, FAS, ICAM1, IL6, NFKBIA, P \\
NF-kappa B signaling pathway & CXCL2, CXCL8, ICAM1, NFKBIA, PTGS2, TLR4, TNF, TNF \\
AGE-RAGE signaling pathway in diabetic complications & CCL2, CXCL8, EDN1, ICAM1, IL6, NOS3, PRKCE, TNF \\
Insulin resistance & IL6, NFKBIA, NOS3, PRKCE, TNF TNFRSF1A \\
Cytokine-cytokine receptor interaction & CCL2, CXCL1, CXCL2, CXCL8, FAS, IL10, IL6, TNF, TNFRS \\
\hline
\end{tabular}


To summarize expression profiling results we generated a heat map by using the average linkage method for all differentially expressed genes of seven CF patients and three non-CF control subjects (Figure 5). Interestingly it was detected that there was a strong correlation between non-CF control subjects and patients with Class IV mutation. Also the similarity of expression results between intermadiate (F3-P2) and severe (F3-P3) patients with Class IV mutation was prominent. The common genes were associated with hepatic involvement. It was concluded that the severity of hepatic involvement was similar between mild and severe patients with Class IV mutation and pathways involved in inflammatory response and protein processing may explain the clinical severity difference between these siblings. Another significant finding was the close correlation established between mild F1-P1 and severe F1-P2 siblings in Family 1. The common genes between F1-P1 and F1-P2 were found to have a role in LPS response, cytokine/chemokine activity and protein binding processes. Also, the upregulated genes in F1-P2, showed a positive correlation with hepatic involvement.

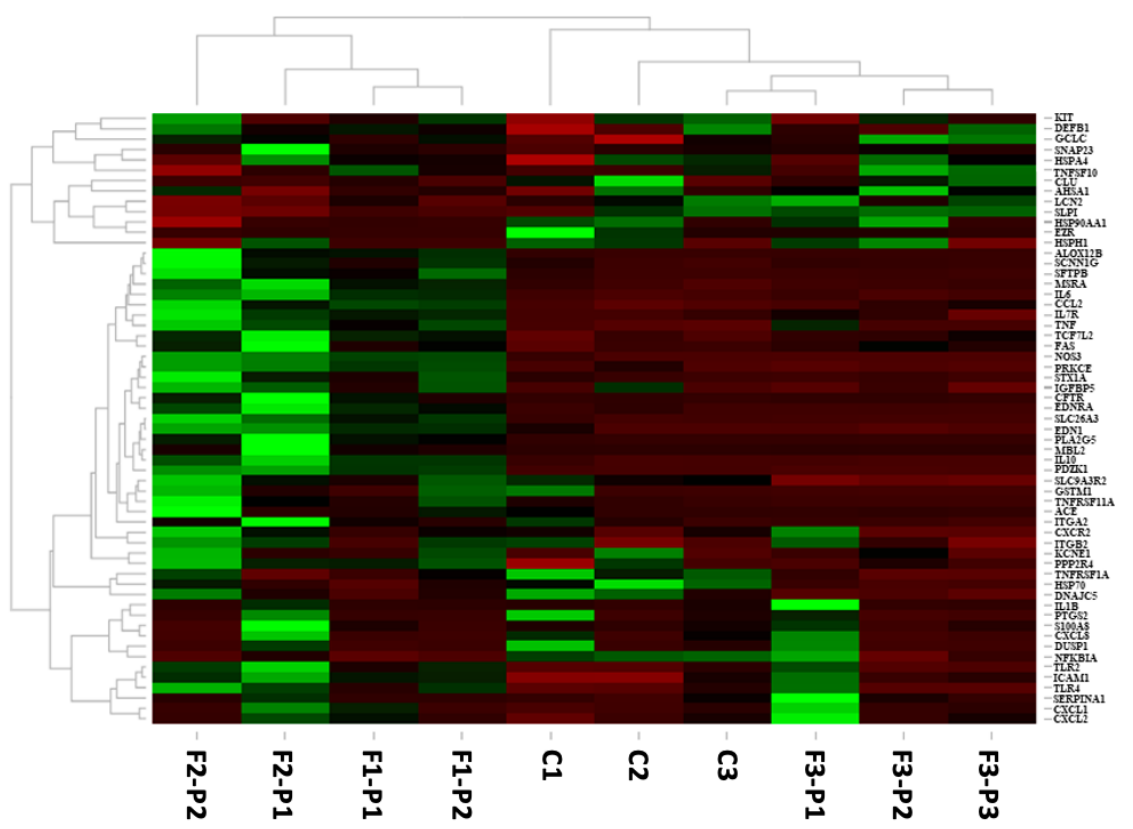

FIGURE 5 Heat map of differentially expressed genes. Each vertical column represents patients and non-CF control subjects, each horizontal column represents gene. The dendrogram was clustered using the average linkage and Spearman rank correlation method (Red represents down regulated genes, green represents upregulated genes.).

\section{Correlation Between Clinical Severity and Differentially Expressed Genes}

In order to investigate whether there is a correlation between clinical parameters determining the disease severity such as recurrent lung infection, FEV1\% values, hepatic involvement, diabetes and differentially expressed genes, bivariate correlation and spearman coefficient method analyses were performed. 29 genes were found to have a significant positive correlation with hepatic involvement. These genes were involved in AGE-RAGE signaling pathway in diabetic complications; $\mathrm{p}=1.62-06$, cytokine-cytokine receptor interaction; $\mathrm{p}=0.0047$, insulin resistance; $\mathrm{p}=0.0077$, TNF signaling pathway; $\mathrm{p}=0.0083$, aldosterone regulated sodium reabsorpsion; $\mathrm{p}=0.0087$, type II diabetes mellitus; $\mathrm{p}=0.0133$ pathways (Figure 6 ). 
A

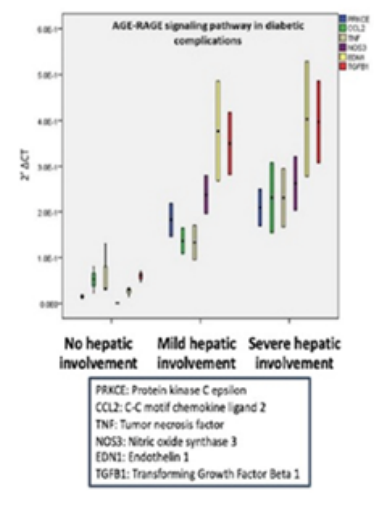

$\mathrm{D}$

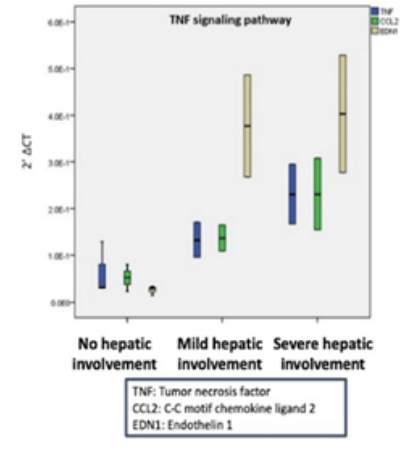

B

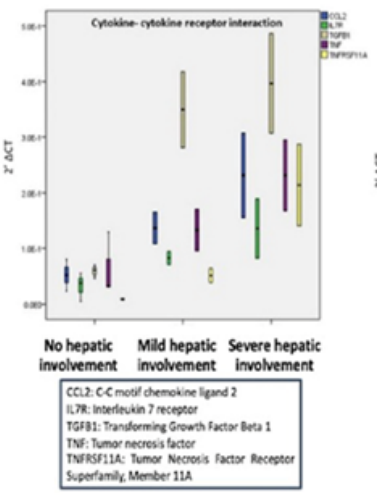

$\mathrm{E}$

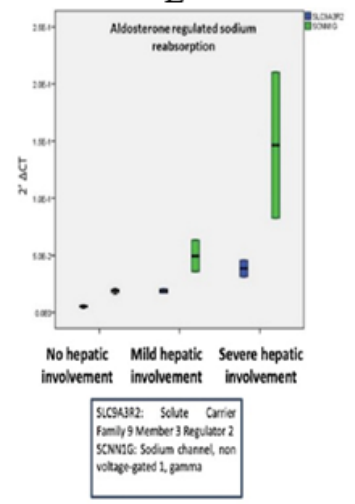

$\mathrm{C}$

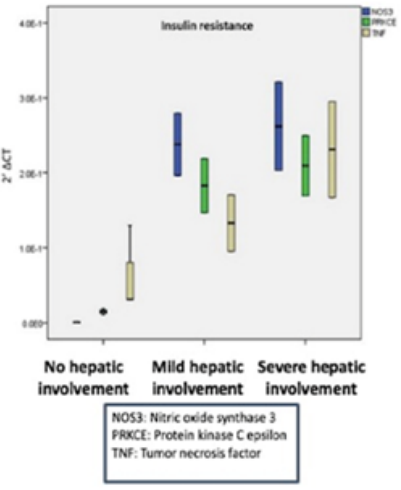

$\mathrm{F}$

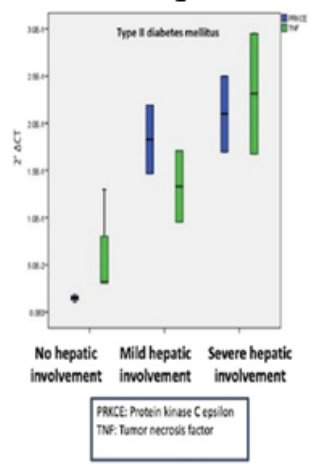

FIGURE 6 Genes involved in pathways that are associated with hepatic involvement (The X axis represents hepatic involvement severity the $\mathrm{Y}$ axis represents the normalized values of the genes. (A) AGE-RAGE signaling pathway in diabetic complications. (B) Cytokine-cytokine receptor interaction (C) Insulin resistance. (D) TNF signaling pathway. (E) Aldosterone regulated sodium reabsorption. (F) Type II diabetes mellitus. Bivariate correlation and spearman coefficient method analyses were performed using the SPSS program (IBM Statistics, Version 22) to establish a correlation between the clinical parameters determining the disease severity. (No hepatic involvement: Family 3, mild hepatic involvement: F1-P1, F2-P1, severe hepatic involvement; F1-P2, F2-P2).

\section{Discussion}

CFTR mutations are one of the factors that determine the severity of $\mathrm{CF} .{ }^{20}$ However, there are many studies performed with patients bearing the same mutation but with different clinical severity. ${ }^{13,14,15,18,19}$ Research regarding clinical heterogeneity in twins and siblings with same CFTR mutation suggests that modifier genes could play a role in disease severity. Studies which use transcriptomic approaches determined that clinical severity is associated with many molecular mechanisms such as CFTR protein folding, function, and trafficking, inflammation, immune response, epithelial cell differentiation, ion transport and oxidative stress.

In a study performed with nasal epithelial cells of F508del homozygotes patients and healthy controls, the expression of genes involved in cell proliferation (MMP1, ADM, AREG, GJA1, RUNX2) was increased and the expression of genes involved in cilia formation (DNAH9, DNAH12, DNAI1, DNAI2 and DNAAF1) was decreased in patients. ${ }^{13}$ In another transcriptomic study, nasal and bronchial samples obtained from same patients have been used, and as a result the primary affected molecular pathways in nasal and bronchial epithelial cells were found to be amino acid metabolism and inflammatory response, respectively. ${ }^{19}$ In another recent study conducted by Kormann et al. it was found that genes involved in type- 1 interferon response and ribosomal stalk proteins that interact with rRNA have an effect on disease severity. ${ }^{18}$ Similar to this 
study, Wright et al. have shown that genes involved in lipid metabolism, protein ubiquitination mechanism, protein metabolism and immune response are related to disease severity. ${ }^{15}$

So far, there is no transcriptomic study that investigates phenotypic variability between mild and severe siblings with the same mutation. In our study we aimed to explain clinical heterogeneity by using targeted transcriptome analysis of nasal epithelial cells to investigate differentially expressed genes and associated pathways of between mild and severe siblings. For this purpose, we determined three families that include siblings with different clinical severity determined by recurrent lung infection, pulmonary involvement and comorbidity. The mutations of Family 1 (F508del/G85E) and Family 2 (F508del/F508del) belonged to Class II group whereas Family 3 (I1234V/I1234V) had mutations of Class IV.

As a result of comparison between mild and severe siblings with Class II mutation, seven genes (TNFRSF11A, KCNE1, STX1A, SLC9A3R2, CXCL1, CFTR, CXCL2) were found to be differentially expressed. TNFRSF11A, KCNE1, STX1A and SLC9A3R2 genes were up regulated while CXCL1, CFTR and CXCL2 genes were down regulated in severe patients. TNFRSF11A also known as NF kappa B activator, is a member of the TNF receptor family and triggers the transcriptional activation of NF kappa B pathway mediated proinflammatory cytokines and chemokines such as CXCL1-2-8 and IL1B. ${ }^{21}$ Similarly, in our study the reason for up regulation of TNFRSF11A ( 4,03 fold), may be to increase the inflammatory response to infection in severe patients with Class II mutation. The mRNA expression of the SLC9A3R2 (2,02 fold) and SCNN1G ( 2,77 fold) genes in the aldosterone regulated sodium reabsorption pathway were also increased in severe patients. Studies have shown that the ion transporters, negative CFTR regulators SCL9A3R2 (SLC9A3 regulator) and SCNN1G (ENaC subunit) are associated with decreased CFTR expression. ${ }^{22,23}$ STX1A was determined in SNARE interactions in vesicular transport pathway. Up regulated STX1A, have been associated with CFTR expression and its conductance. ${ }^{24,25}$ The decreased expression of CXCL1 (-5,03 fold), CXCL2 (-2,65 fold), IL1B (-3,22 fold), CXCL8 (-10,59 fold), HSP90AA1 (-2,09) and PTGS2 (-3,61 fold) in inflammation related pathways (IL-17 signaling, NF-kappa B signaling, cytokine-cytokine receptor interaction, TNF signaling, NOD-like receptor signaling and, chemokine signaling pathways) suggested that the inflammatory response could be suppressed in severe patients with Class II mutation. Some studies have shown increased expression of chemokines and cytokines detected in CF patients compared to controls. ${ }^{13,19,26}$ But some reported conflicting results, similar to our findings. Ideozu et al. showed that the expression of CXCL1 and IL1B were decreased in CF patients compared to healthy controls. ${ }^{27}$ Similar to this study, Kormann et al. and Wright et al. showed that CXCL8 expression was decreased in severe CF patients. ${ }^{15,18}$ In our study, the decreased chemokine expression detected in severe patients with Class II mutation could also be related to endoplasmic reticulum stress and chemokine secretion. ${ }^{28}$ Pathway enrichment analysis showed that NOD-like receptor signaling pathway was among the most prominent ones. Significantly down regulated CXCL1 and CXCL2 genes were found to be functional in NOD-like receptor signaling pathway in severe patients. In a study conducted on primary bronchial epithelial cell culture and monocytes of CF patients, it was detected that as a result of decreased CFTR protein expression, ENaC expression was increased. This caused stimulation of NLRP3 inflammasome and the release of IL18 and IL1B. ${ }^{29}$ This finding supported the formation of the inflamasomme mechanism in nasal epithelial cells. ${ }^{29,30}$ The decrease in the expression of genes in this pathway in severe patients could be elucidated by the decreased CFTR expression and ER stress.

In Class IV group, 24 genes (Up regulated 3 genes, down regulated 21 genes) were found to be differentially expressed in severe sibling. Since Class IV group consisted of only one family (3 siblings), the statistical significance of differentially expressed genes could not be evaluated and the pathways were interpreted by means of biological significance. As a result of pathway analysis, different from the Class II group, specific to the Class IV group, AGE-RAGE signaling pathways in diabetic complications and TLR signaling pathways were found. Especially, the AGE-RAGE signaling pathway in diabetic complications was the most important pathway in the severe patient. AGE-RAGE interaction triggers the activation of inflammation-related pathways such as NF-kappa B signaling. ${ }^{31}$ CCL2, CXCL8, TNF and IL1B were included in this pathway and were found to be down regulated in the severe patient (F3-P3). NF kappa B signaling pathway associated inflammation has suggested that in this patient the inflammatory response may be suppressed. Also, NOS3 
gene was identified in the AGE-RAGE signaling pathway and played a role in caspase-3 activation.

In order to identify common differentially expressed genes between severe patients with Class II mutation and severe patients with Class IV mutation Venn diagram was created. 13 genes (KCNE1, ACE, CFTR, SFTPB, CXCR2, CXCL1, CXCL8, IL1B, PLA2G5, HSP90AA1, DUSP1, PTGS2, MBL2) which were found to be common between Class II and Class IV severe patients show that their expression change independent of mutation type (Figure S1). Gene Ontology (GO) analysis showed that the common genes were involved in neutrophil chemotaxis and regulation, inflammation response, chemokine signaling pathway and immune response-related processes.

As a result of heat map interpretation, it was an interesting finding that controls demonstrated similar gene expression profiles with mild Class IV group with I1234V mutation. F3-P1, which is the mildest sibling in the Class IV group, has a close relationship with C3. The common up and down regulated genes between intermediate F3-P2 and severe F3-P3 siblings with Class IV mutation, were associated with hepatic involvement. In addition, 17 genes (KIT, DEFB1, SNAP23, HSPA4, CLU, AHSA1, LCN2, HSP90AA1, EZR, HSPH1, CCL2, TCF7L2, FAS, KCNE1, PPP2R4, SERPINA1 and CXCL2) which showed distinct expression pattern between F3-P2 and F3-P3 were responsible for cell chemotaxis, inflammation, immune response, protein folding, stabilization, TNF, chemokine and IL-17 signaling pathways. Also, it can be concluded that inflammation and protein processing mechanisms may explain the clinical severity between intermediate F3-P2 and severe F3-P3 siblings with Class IV mutation. Another significant finding in the heat map was the close correlation of mild F1-P1 and severe F1-P2 in Family 1. Genes that showed a similar expression profile in Family 1, were the ones responsible for LPS response, cytokine-chemokine activity and protein folding processing mechanism. On the other hand, 32 genes which were differentially expressed between mild and severe siblings in Family 1 were associated with hepatic involvement and may have a role in determining clinical severity.

In order to investigate whether there was an association between clinical parameters (recurrent lung infection, FEV1\%, hepatic involvement, CFRD) and differentially expressed genes in all CF patients, correlation analysis was performed. The increase in expression of 29 genes was found to have a significant correlation with an increase in severe hepatic involvement and liver inflammation. Among the significant pathways, AGERAGE signaling pathways in diabetic complications (PRKCE, CCL2, TNF, NOS3, EDN1 and TGFB1) was determined as the most outstanding one and may be regarded as a prognostic biomarker for CFLD which is characterized by focal biliary cirrhosis and occurs in 5-10\% of patients with CF. ${ }^{32}$ A recent study performed by Paranjapye et al. has determined ABCA4, GSTP1, MBL2 and SERPINA1 as modifier genes for CFLD. ${ }^{33}$ Also, Debray et al. has confirmed SERPINA1 as a modifier gene for severe CFLD. ${ }^{34}$ Also they concluded that ACE, TGFB1 and CXCL8 could be associated with CFLD severity. However, in our study, we did not find an association between ABCA4, GSTP1, MBL2 and SERPINA1 genes and hepatic involvement in CF patients. We also showed that ACE and TGFB1 had a positive correlation with hepatic involvement.

\section{Conclusion}

In this study, the molecular mechanisms and related pathways that may cause clinical severity among mild and severe CF siblings with same genotype were identified. The data obtained as a result of this study will provide opportunity for identification and development of new target molecules for treatment in the future. Also determination of candidate genes will pave the way for their use for both prognostic and therapeutic biomarkers especially for preventing the progression of hepatic involvement. Determination of differentially expressed genes and associated pathways between $\mathrm{CF}$ patients and controls may provide new insights into molecular pathology of not only CF but also other respiratory diseases.

\section{References}

1. Cutting GR. Cystic fibrosis genetics: from molecular understanding to clinical application . Nat Rev Genet. 2015;16(1):45-56.

2. Pereira SV, Ribeiro JD, Ribeiro AF, Bertuzzo CS, Marson FAL.Novel, rare and common pathogenic variants in the CFTR gene screened by high-throughput sequencing technology and predicted by in silico 
tools . Sci Rep. 2019;17(9):1-16.

3. Bombieri C, Claustres M, De Boeck K, Derichs N, Dodge J, Girodon E, et al. Recommendations for the classification of diseases as CFTR related disorders. J Cyst Fibros. 2011;10(Suppl 2):86-102.

4. Justicia JL, Sole A, Quintana-Gallego E, Gartner S, de Gracia J,Prados C, Ma iz L. Management of pulmonary exacerbations in cystic fibrosis: still an unmet medical need in clinical practice. Expert Rev Respir Med. 2015;9(2):183-94.

5. Illing EA, Woodworth BA. Management of the upper airway in cystic fibrosis . Curr Opin Pulm Med. 2014;20(6):623-31.

6. Cipolli M, Castellani C, Wilcken B, Massie J, McKay K, GrucaM, et al.Pancreatic phenotype in infants with cystic fibrosis identified by mutation screening . Arch Dis Child. 2007;92(10):842-84.

7. Park HW, Nam JH, Kim JY, Namkung W, Yoon JS, Lee JS, et al.Dynamic regulation of CFTR bicarbonate permeability by $\mathrm{Cl}$ - and its role in pancreatic bicarbonate secretion. Gastroenterology. 2010;139(2):620-31.

8. Moran A, Pillay K, Becker D, Granados A, Hameed S, Acerini CL.ISPAD Clinical Practice Consensus Guidelines 2018: Management of cystic fibrosis-related diabetes in children and adolescents. Pediatr Diabetes. 2018;19(Suppl 27):64-74.

9. Dupuis A, Keenan K, Ooi CY, Dorfman R, Sontag MK, Naehrlich L, et al.Prevalence of meconium ileus marks the severity of mutations of the cystic fibrosis transmembrane conductance regulator (CFTR) gene. Genet Med. 2016;18(4):333-40.

10. Flass T, Narkewicz MR. Cirrhosis and other liver disease in cystic fibrosis. J Cyst Fibros. $2013 ; 12(2): 116-24$.

11. Dayangac D, Erdem H, Yilmaz E, Sahin A, Sohn C, Ozguc M, et al.Mutations of the CFTR gene in Turkish patients with congenital bilateral absence of the vas deferens . Hum Reprod. 2004;19(5):1094100.

12. Costes B, Girodon E, Ghanem N, Flori E, Jardin A, Soufir JC et al.Frequent occurrence of the CFTR intron $8(T G) n 5 T$ allele in men with congenital bilateral absence of the vas deferens. Eur J Hum Genet. 1995;3(5):285-93.

13. Clarke LA, Sousa L, Baretto C, Amaral MD. Changes in nasal transcriptome of native nasal epithelium expressing F508del-CFTR and intersecting data from comparable studies . Respir Res. 2013;14(38):119.

14. Clarke LA, Botelho HM, Sousa L, Falcao AO, Amaral MD. Transcriptome meta-analysis reveals common differential and global gene expression profiles in cystic fibrosis and other respiratory disorders and identifies CFTR regulators. Genomics. 2015;106(5):268-77.

15. Wright JM, Merlo CA, Reynolds JB, Zeitlin PL, Garcia JG, Guggino WB, et al. Respiratory epithelial gene expression in patients with mild and severe cystic fibrosis lung disease. Am J Respir Cell Mol Biol. 2006;35(3):327-36.

16. Mekus F, Ballmann M, Bronsveld I, Bijman J, Veeze H, Tummler B.Categories of delta F508 homozygous cystic fibrosis twin and sibling pairs with distinct phenotypic characteristics. Twin Res. 2000;3(4):277-93.

17. Terlizzi V, Lucarelli M, Salvatore D, Angioni A, Bisogno A, Braggion C, et al. Clinical expression of cystic fibrosis in a large cohort of Italian siblings . BMC Pul Med. 2018;18(1):1-8.

18. Kormann MSD, Dewerth A, Eichner F, Baskaran P, Hector A, Regamey N, et al. Transcriptomic profile of cystic fibrosis patients identifies type I interferon response and ribosomal stalk proteins as potential modifiers of disease severity . PLoS One. 2017;12(8):1-13.

19. Ogilvie V, Passmore M, Hyndman L, Jones L, Stevenson B, Wilson A, et al. Differential global gene expression in cystic fibrosis nasal and bronchial epithelium. Genomics. 2011;98(5):327-36.

20. Cutting GR. Modifier genes in Mendelian disorders: the example of cystic fibrosis. Ann N Y Acad Sci. 2010;1214(1):57-69.

21. Monin L, Gaffen SL. IL-17 family cytokines: signaling mechanisms, biological activities and therapeutic implications . Cold Spring Harb Perspect Med. 2018;10(4):1-24.

22. Hobbs CA, Da Tan C, Tarran R. Does epithelial sodium channel hyperactivity contribute to cystic 
fibrosis lung disease? J Physiol. 2013;591(18):4377-87.

23. Singh AK, Riederer B, Krabbenhoft A, Rausch B, Bonhagen J, Lehmann U, et al. Differential roles of NHERF1, NHERF2, and PDZK1 in regulating CFTR-mediated intestinal anion secretion in mice . J Clin Invest. 2009;119(3):540-50.

24. Ganeshan R, Di A, Nelson DJ, Quick MW, Kirk KL. The interaction between syntaxin $1 A$ and cystic fibrosis transmembrane conductance regulator $\mathrm{Cl}$ - channels is mechanistically distinct from syntaxin 1A-SNARE interactions. J Biol Chem. 2003;278(5):2876-85.

25. Boyaka E, Di A, Chang SY, Naren AP, Tousson A, Nelson DJ, et al.CFTR chloride channels are regulated by a SNAP-23/syntaxin 1A complex . Proc Natl Acad Sci USA. 2002;99(19):12477-82.

26. Chu CY, Qiu X, Wang L, Bhattacharya S, Lofthus G, Corbett A, et al.The Healthy Infant Nasal Transcriptome: A Benchmark Study. Sci Rep. 2016;23(6):1-10.

27. Ideozu JE, Rangaraj V, Abdala-Valencia H, Zhang X, Kandpal M, Sala MA, et al. Transcriptional consequences of impaired immune cell responses induced by cystic fibrosis plasma characterized via dual RNA sequencing. BMC Med Genomics. 2019;12(1):1-16.

28. Tang AC, Saferali A, He G, Sandford AJ, Strug LJ, Turvey SE.Endoplasmic Reticulum Stress and Chemokine Production in Cystic Fibrosis Airway Cells: Regulation by STAT3 Modulation. J Infect Dis. 2017;215(2):293-302.

29. Scambler T, Griffiths HJ, Reyna S, Pathak S, Wong C, Holbrook J, et al. ENaC-mediated sodium influx drives NLRP3 inflammasome- dependent autoinflammation in cystic fibrosis . eLife. 2019;8:e49248

30. McElvaney OJ, Zaslona Z, Becker-Flegler K, Palsson-McDermott EM, Boland F, Gunaratnam C, et al. Specific Inhibition of the NLRP3 Inflammasome as an Anti-Inflammatory Strategy in Cystic Fibrosis .Am J Respir Crit Care Med. 2019;200(11):1381-91.

31. Yamagishi S, Matsui T. Role of receptor for advanced glycation end products (RAGE) in liver disease . Eur J Med Res. 2015;20(1):1-7.

32. Stonebraker JR, Ooi CY, Pace RG, Corvol H, Knowles MR, Durie PR, et al. Features of severe liver disease with portal hypertension in patients with cystic fibrosis . Clin Gastroenterol Hepatol. 2016; 14(8):1207-15.

33. Paranjapye A, Ruffin M, Harris A, Corvol H. Genetic Variation in CFTR and Modifier Loci May Modulate Cystic Fibrosis Disease Severity . J Cyst Fibros. 2020;19(Suppl 1):10-14.

34. Debray D, Corvol H, Housset C. Modifier genes in cystic fibrosis-related liver disease. Curr Opin Gastroenterol.2019;35(2):88-92.

\section{SUPPORTING INFORMATION}

TABLE S1 Differentially expressed genes with severe patients in Class II mutation. (Significantly up/down regulated genes are shown in bold.)

\begin{tabular}{lll}
\hline Up regulated genes & Description & Fold change \\
\hline GSTM1 & Glutathione S-transferase mu 1 & 15,19 \\
ACE & Angiotensin I converting enzyme 1 & 8,22 \\
TNFRSF11A & TNF receptor superfamily member 11A & 4,03 \\
KCNE1 & Potassium voltage-gated channel, member 1 & 3,90 \\
SFTPB & Surfactant protein B & 3,45 \\
STX1A & Syntaxin 1A & 3,03 \\
SCNN1G & Sodium channel, nonvoltage-gated 1, gamma & 2,77 \\
ALOX12B & Arachidonate 12-lipoxygenase, 12R type & 2,61 \\
AHSA1 & Activator of heat shock 90kDa protein ATPase homolog 1 & 2,36 \\
CXCR2 & C-X-C motif chemokine receptor 2 & 2,34 \\
TNFRSF1A & TNF receptor superfamily member 1A & 2,22 \\
KIT & KIT proto-oncogen receptor tyrosine kinase & 2,19 \\
SLC9A3R2 & Solute carrier family 9, member 3 regulator 2 & 2,02 \\
Down regulated genes & Description & Fold change
\end{tabular}




\begin{tabular}{lll}
\hline Up regulated genes & Description & Fold change \\
\hline S100A8 & S100 calcium binding protein A8 & $-18,44$ \\
CXCL8 & C-X-C motif chemokine ligand 8 & $-10,59$ \\
CXCL1 & C-X-C motif chemokine ligand 1 & $-5,03$ \\
LCN2 & Lipocalin 2 & $-4,56$ \\
MBL2 & Mannose binding lectin 2 & $-4,47$ \\
PTGS2 & Prostaglandin-endoperoxide synthase 2 & $-3,61$ \\
SNAP23 & Synaptosome associated protein 23kDa & -3.27 \\
IL1B & Interleukin 1 beta & $-3,22$ \\
CFTR & Cystic fibrosis transmembrane conductance regulator & $-2,92$ \\
TNFSF10 & TNF superfamily member 10 & $-2,75$ \\
CXCL2 & C-X-C motif chemokine ligand 2 & $-2,65$ \\
ITGA2 & Integrin alpha 2 & $-2,47$ \\
SLPI & Secratory leukocyte peptidase inhibitor & $-2,42$ \\
DUSP1 & Dual specificity phosphatase 1 & $-2,25$ \\
PLA2G5 & Phospholipase A2 group 5 & $-2,24$ \\
HSP90AA1 & Heat shock protein 90 alpha family class A member 1 & $-2,09$ \\
\hline
\end{tabular}

\begin{tabular}{llc}
\hline Up regulated genes & Description & Fold char \\
\hline GCLC & Glutamate-cysteine ligase, catalytic subunit & 11,52 \\
IL6 & Interleukin 6 & 9,60 \\
CCL2 & C-C motif chemokine ligand 2 & 9,01 \\
ALOX12B & Arachidonate 12-lipoxygenase & 6,39 \\
SFTPB & Surfactant protein B & 6,38 \\
CFTR & Cystic fibrosis transmembrane conductance regulator & 6,30 \\
TNF & Tumor necrosis factor & 5,50 \\
IL10 & Interleukin 10 & 4,67 \\
SLC26A3 & Solute carrier family 26, member 3 & 4,45 \\
ICAM1 & Intercellular adhesion molecule 1 & 4,29 \\
CXCL2 & C-X-C motif chemokine ligand 2 & 3,97 \\
MBL2 & Mannose-binding lectin 2 & 3,96 \\
MSRA & Methionine sulfoxide reductase A & 3,90 \\
FAS & Fas & 3,68 \\
NOS3 & Nitric oxide synthase 3 & 3,21 \\
PDZK1 & PDZ domain containing 1 & 3,28 \\
EDNRA & Endothelin receptor type A & 3,16 \\
SNAP23 & Synaptosome associated protein 23 kDa & 3,07 \\
TLR4 & Toll-like receptor 4 & 2,88 \\
TCF7L2 & Transcription factor 7-like 2 & 2,87 \\
CXCL1 & C-X-C motif chemokine ligand 1 & 2,80 \\
SCNN1G & Sodium channel, nonvoltage-gated 1, gamma & 2,75 \\
HSPA4 & Phospholipase A2 group 5 & 2,62
\end{tabular}




\begin{tabular}{llc}
\hline Up regulated genes & Description & Fold char \\
\hline Down regulated genes & Description & Fold char \\
EZR & Ezrin & $-7,27$ \\
NFKBIA & Nuclear factor of kappa light polypeptide gene enhancer in B-cells inhibitor, alpha & $-2,84$ \\
PTGS2 & Prostaglandin-endoperoxide synthase 2 & $-2,58$ \\
TNFRSF1A & TNF receptor superfamily member 1A & $-2,43$ \\
HSPA1A & Heat shock 70kDa protein 1A & $-2,39$ \\
LCN2 & Lipocalin 2 & $-2,27$ \\
SLPI & Secretory leukocyte peptidase inhibitor & $-2,26$ \\
CXCL8 & C-X-C motif chemokine ligand 8 & $-2,08$ \\
DNAJC5 & DnaJ homolog, subfamily C, member 5 & $-2,00$ \\
\hline
\end{tabular}

TABLE S2. Differentially expressed genes in patients (Family 1, 2 and 3) compared to healthy controls. (Significantly up/down regulated genes are shown in bold.)

\section{Class II Class IV}

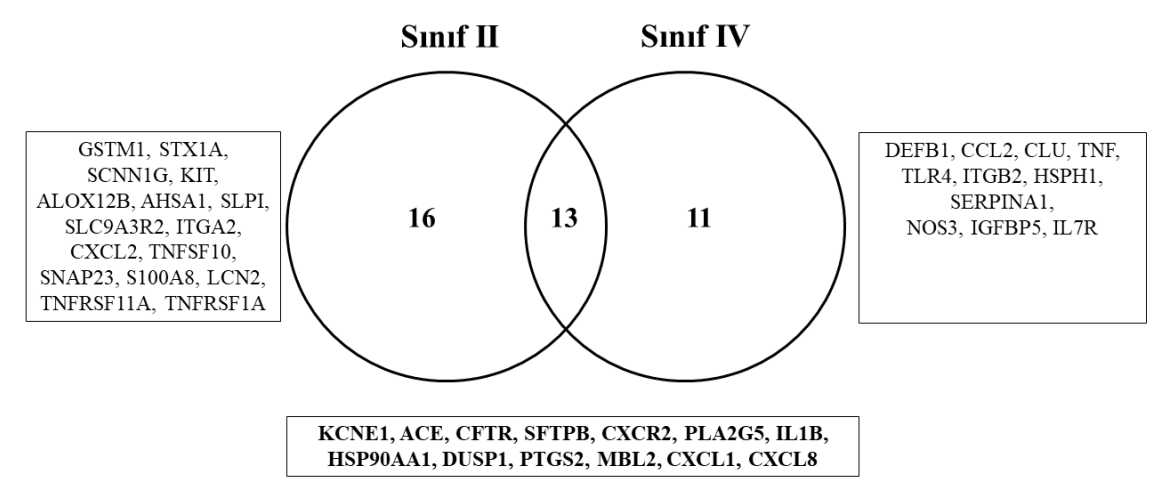

FIGURE S1. The Venn diagram of differentially expressed genes in Class II and Class IV group severe patients (Differentially expressed 13 genes are shown in bold.). 


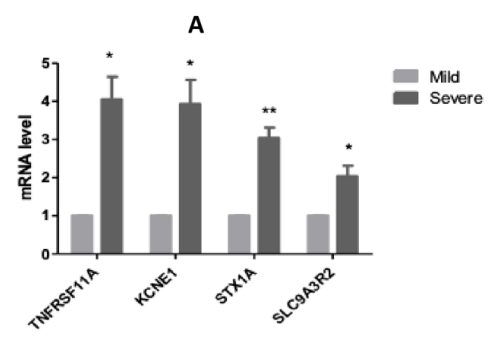

B
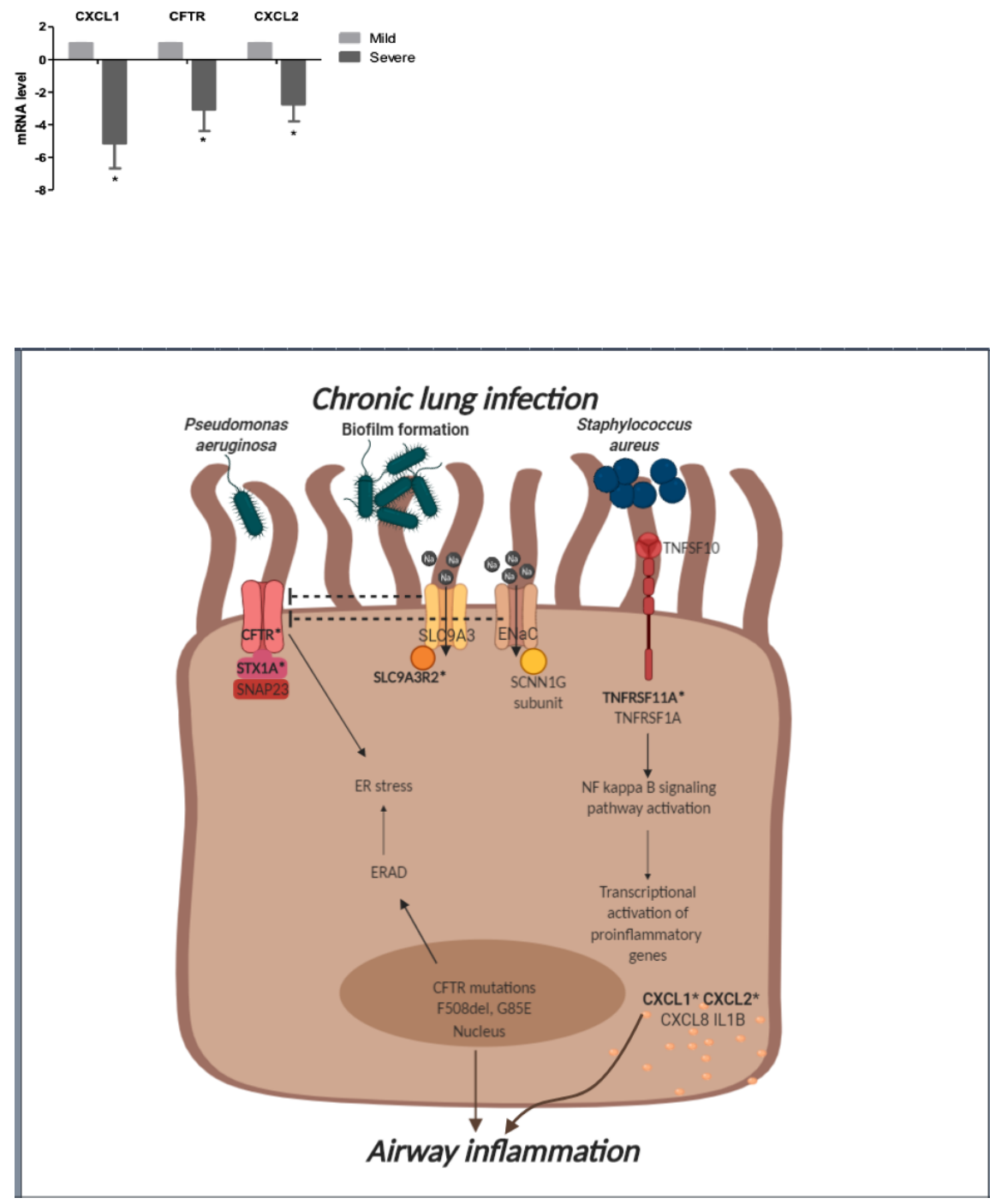


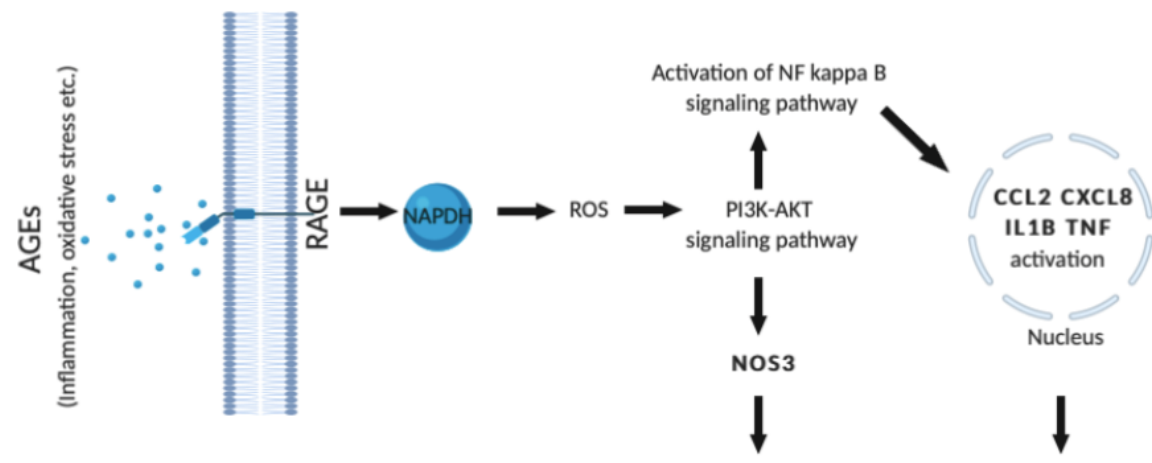

Caspase- 3 mediated apotosis

Inflammation

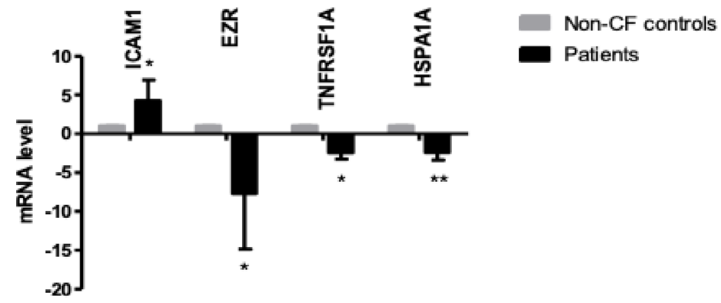




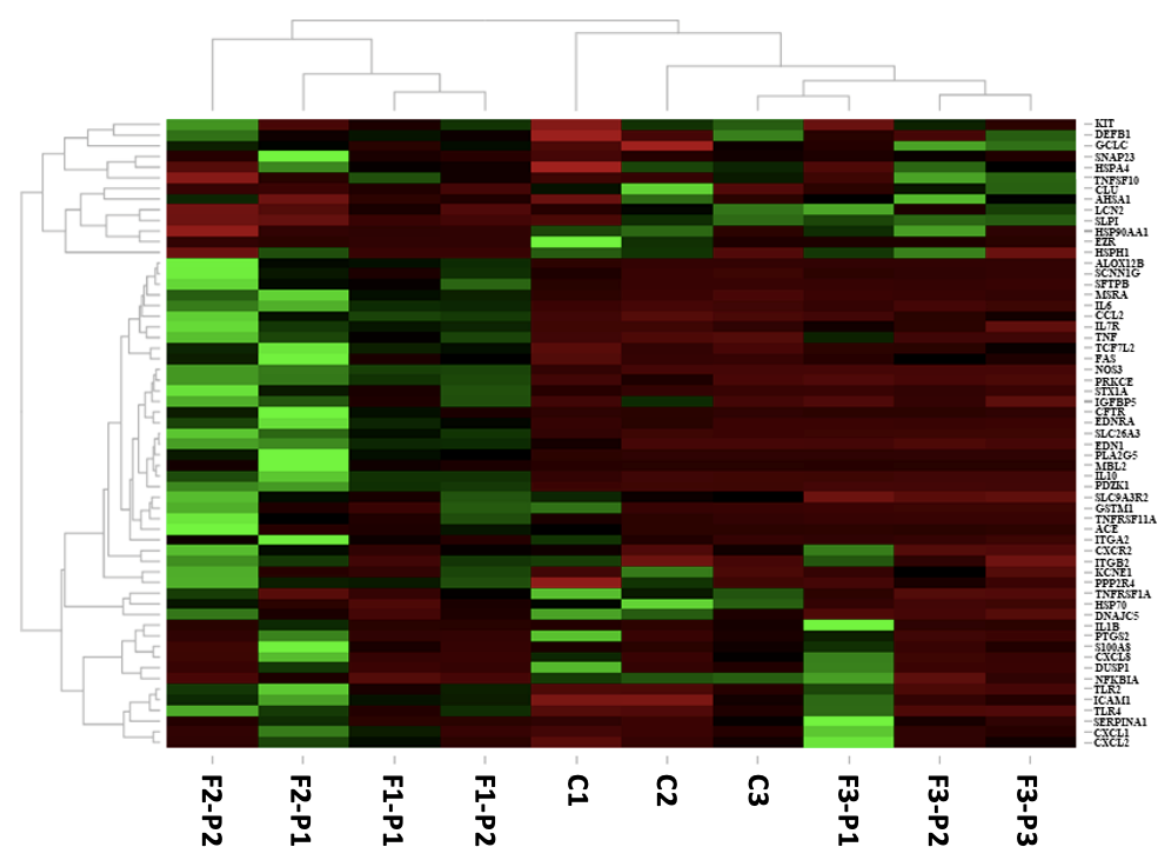

A

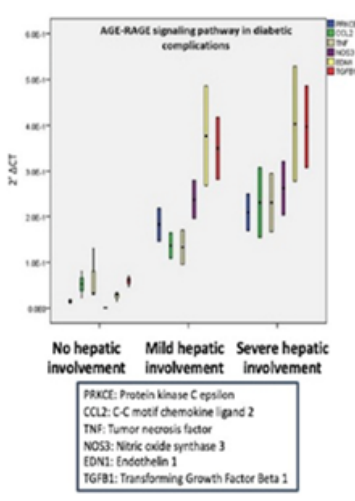

D

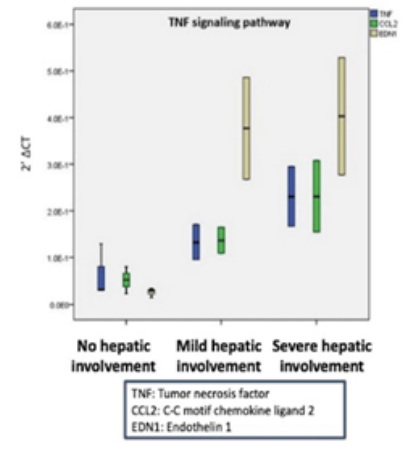

B

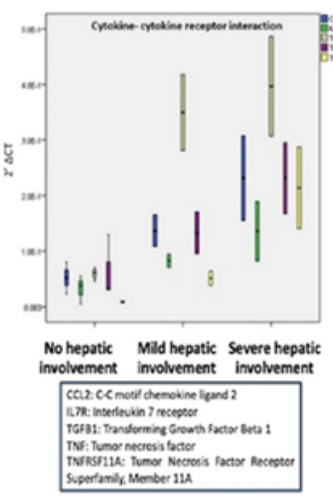

E

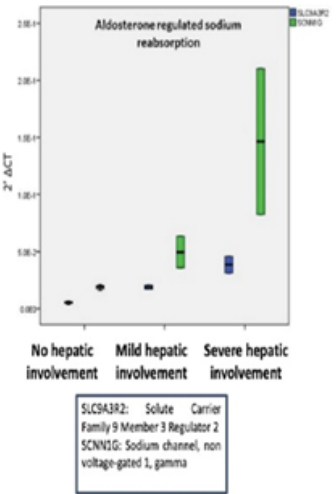

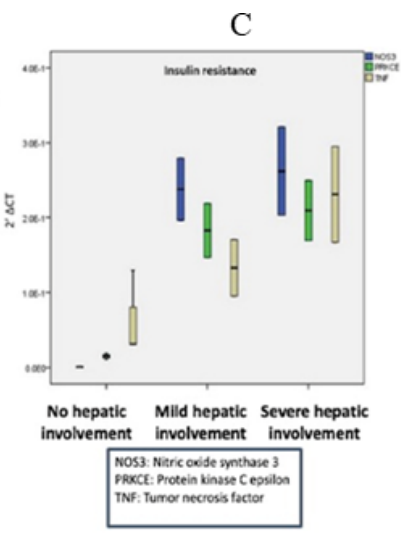

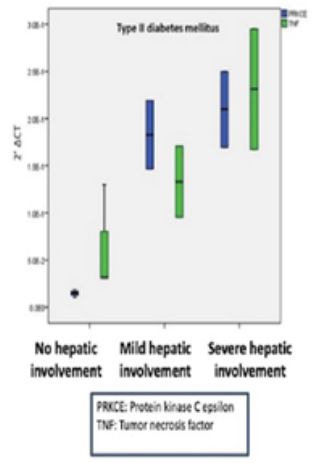

Hosted file

Table 1.docx available at https://authorea.com/users/341719/articles/468616-differential- 
expressed-genes-and-pathways-associated-with-disease-severity-in-siblings-with-cysticfibrosis

\section{Hosted file}

Table 2.docx available at https://authorea.com/users/341719/articles/468616-differentialexpressed-genes-and-pathways-associated-with-disease-severity-in-siblings-with-cysticfibrosis

\section{Hosted file}

Table 3.docx available at https://authorea.com/users/341719/articles/468616-differentialexpressed-genes-and-pathways-associated-with-disease-severity-in-siblings-with-cysticfibrosis

\section{Hosted file}

Table 4.docx available at https://authorea.com/users/341719/articles/468616-differentialexpressed-genes-and-pathways-associated-with-disease-severity-in-siblings-with-cysticfibrosis 